ISSN: 1130-3743 - ISSN electrónico: 2386-5660

DOI: http://dx.doi.org/10.14201/teoredu20152724570

\title{
EL «ENFOQUE DE LAS CAPACIDADES» DE MARTHA NUSSBAUM Y SUS CONSECUENCIAS EDUCATIVAS: HACIA UNA PEDAGOGÍA SOCRÁTICA Y PLURALISTA
}

\author{
The Martha Nussbaum's "capability approach" and \\ its educational consequences: towards a socratic and \\ pluralistic pedagogy
}

\section{L' "approche des capabilités" de Martha Nussbaum et ses conséquences en matière d'éducation: vers une pédagogie socratique et pluraliste}

\author{
Virginia Guichot-ReinA \\ Universidad de Sevilla. Facultad de Ciencias de la Educación. \\ Departamento de Teoría e Historia de la Educación y Pedagogía Social. \\ C/Pirotecnia,s/n.41013Sevilla.guichot@us.es
}

Fecha de recepción: marzo de 2015

Fecha de aceptación: junio de 2015

Biblid [(1130-3743) 27, 2-2015, 45-70]

RESUMEN

En un tiempo de incertidumbre como el que vivimos, la educación corre el riesgo de perderse en un sinfín de propuestas sin que exista un debate riguroso acerca de una pregunta esencial para cualquier educador: cuál es el modelo de persona y de sociedad por el que apuesta, y hacia el que se han de dirigir todas sus acciones educativas. En este artículo, intentamos salvar ese importante déficit presentando el «enfoque de las capacidades» de Martha Nussbaum, que incluye una determinada teoría de la justicia social y del bienestar individual. A partir de dicho marco, 
Nussbaum presenta algunas líneas fundamentales que deberá recoger la educación: la de contribuir a formar el pensamiento crítico y reflexivo y la de ser pluralista y formarnos en una ciudadanía múltiple o compleja. Concluimos con unas reflexiones personales acerca del difícil camino que debemos recorrer si nos comprometemos con el logro de esa «sociedad justa» de Nussbaum.

Palabras clave: Enfoque de las capacidades y educación; Filosofía de la educación de Martha Nussbaum; Educación para la ciudadanía; Pensamiento educativo contemporáneo; Educación moral.

\section{SUMMARY}

In a time of uncertainty such as the one we are currently living through, education can become lost beneath an avalanche of proposals unless rigorous debate is maintained on one essential question for an educator: which model of person and society should be chosen towards which all educational actions should be directed. This paper strives to clarify this choice. We show the Martha Nussbaum's approach which includes a theory of social justice and individual well-being. Within this framework, Nussbaum defends several essential characteristics that education must pursue: provision of critical and reflective thinking; and pluralism and training for a complex citizenship. This article is completed with personal conclusions concerning the difficult journey one has to travel upon accepting commitment towards Nussbaum's "fair society".

Key words: "Capability Approach" and Education; Martha Nussbaum's Educational Philosophy; Citizenship Education; Contemporary Educational Thinking; Moral Education.

\section{SOMMAIRE}

Dans cette époque d'incertitude où nous habitons, l'éducation est en danger de se perdre dans un grand nombre de propositions sans avoir eu un débat sérieux sur une question essentielle pour un éducateur: Quel est le modèle d'être humain et de société par lequel parie et auquel il doit destiner toutes ses activités éducatives. Dans cet article, nous essayons de sauver ce déficit en présentant l'approche des "capabilités» de Martha Nussbaum, qui comprend une théorie particulière de la justice sociale et de bien-être personnel. Dans ce contexte, Nussbaum introduit quelques lignes fondamentales que l'éducation devrait recueillir: il faut qu'elle encourage la pensée critique et réflexive et elle doit être pluraliste et nous former à une citoyenneté multiple ou complexe. À la fin, nous offrons quelques réflexions personnelles sur le difficil chemin que nous devons parcourir si nous nous sommes engagés à la réalisation de cette " société juste " de Nussbaum. 
Mots clés: "Approche des capabilités» et éducation; Philosophie de l'éducation de Martha Nussbaum; Éducation à la citoyenneté; Pensée educative contemporaine; Éducation morale.

\section{INTRODUCCIÓN}

"Nunca corren buenos tiempos para quien no sabe adónde va", sentenciaba Séneca. Vivimos en un contexto convulso e incierto, en el que la mayoría de nuestras seguridades se han tambaleado. Si hay un término protagonista en los últimos años, un vocablo que aparece diariamente en todos los medios de comunicación y en las conversaciones cotidianas de la mayor parte de los occidentales es el de crisis, que no es sólo económica o financiera, sino también, como señala Sampedro, política y moral (Sampedro, 2011, 16). El origen más inmediato de la crisis y su desarrollo es bien sabido. Aprovechando la burbuja inmobiliaria y para obtener cada vez más recursos para seguir creando deuda -el gran negocio de los bancos-, éstos vendían los contratos hipotecarios. Pero lo que se inició como un negocio bueno y seguro, que daba rendimientos extraordinarios a inversores de todo el mundo, comenzó a cambiar cuando los bancos empezaron a colocar en los mercados millones de hipotecas muy arriesgadas de personas que dejarían de poder pagarlas si se modificaba su situación a peor. Cuando esto ocurrió, las iniciales hipotecas y los sucesivos productos que se iban creando a partir de ellas se convirtieron en basura financiera que arruinaba a quien hubiera invertido en ellas, como les pasó a miles de bancos e inversores (Torres, 2011). Pero la crisis, además de económica, es política. Aunque la crisis financiera estalló por el abuso de los beneficios, el hecho de que los daños no los hayan sufrido tanto los causantes como sus víctimas (con pérdidas o con desempleo) es consecuencia de la estructura del sistema, cuyas reglas permitieron los atropellos y cuyas autoridades no los controlaron a tiempo. Como subraya Sampedro, "la raíz de los daños no radica en los préstamos mismos, sino en el poder dominante de los bancos, libres para poner condiciones al crédito. Más que un problema económico se trata de una desigualdad de poder, un hecho político que, si no se remedia, provocará crisis ulteriores" (Sampedro, 2011, 19).

La crisis es también moral: los valores democráticos, los principios éticos en los que se basa -la justicia social, en primer lugar-, se han sustituido por el mercado. Se ha olvidado por completo que la «libertad de mercado [...] tiene que incluir otras libertades imprescindibles, de cumplimiento conminatorio: la libertad de comer, de beber agua potable, de vivir, de educarse, tener acceso a la sanidad, a la justicia, a la cultura, a pensar y a expresarse, a estar verazmente informados. Todos. La libertad no puede ligarse únicamente al beneficio económico» (Artal, 2011, 109). Hemos llegado hasta el punto de que hablar de moral, de ética, de valores humanos que todos, y principalmente, con más responsabilidad, los dirigentes públicos deben respetar, se considera un acto de ingenuidad y provoca sonrisas de compasión por la candidez de quien apela a esos términos. Ello lleva 
a pensadores humanistas como José Luis Sampedro a hablar de «crisis del sistema de vida occidental» y a emitir palabras tan duras como las siguientes:

Pero lo más grave y lo más destructivo para una civilización es, en mi opinión, la pérdida de los valores morales superiores y, con ello, de las más altas referencias para la conducta humana. Esa decadencia es la máxima barbarie y es muy perceptible en la situación actual. El alto ideal de justicia, por ejemplo, aparece viciado con frecuencia y, sobre todo, el derecho internacional ha sido violado repetidamente, según ocurrió con Irak. El desdén por la difusión de la educación y la sanidad en los países más pobres, la sobreexplotación de los más débiles, como la infancia o la mujer, violan valores, supeditándolos a los intereses materiales. El concepto de libertad es tergiversado de forma irresponsable para permitir abusos de los poderosos, como ocurre en la desregulación financiera o en la globalización incontrolada. Más que en la economía de mercado vivimos en una sociedad de mercado, donde todo tiene su precio en vez de considerarse su valor. El sistema, como expresó tajantemente Marx, lo convierte todo en mercancía. Ejemplo de ello es la corrupción generalizada que, en definitiva, significa que hasta los hombres mismos (y los más responsables por los puestos que ocupan) se ofrecen en venta a otros dispuestos a comprarlos. Y lo que es peor, ese tráfico ya ni siquiera escandaliza, se toma como algo natural, sin repercusión electoral alguna (Sampedro, 2011, 18).

Ante esta situación, la responsabilidad de toda la ciudadanía es asumir el deber de construir una sociedad en la que todos disfruten de unos mínimos de calidad de vida, en la que la justicia social sea una realidad sentida y vivida por la población, en la que el término "libertad" no se identifique con «elegir el producto de consumo» y se asocie a autonomía crítica, responsable y solidaria, en la que la participación sea cualificada y se anime a todos y no sólo a un grupo privilegiado a tomar las riendas del devenir político. Habrá que comprometerse sinceramente en dejar ya a un lado democracias simplemente formales, y luchar por que la utopía democrática (fuerza de ideales como la participación activa, la igualdad civil, política y material, la libertad, la solidaridad, la justicia) deje de serlo para transformarse en una realidad más de nuestra vida cotidiana.

En este contexto es en el que planteamos este artículo. Con frecuencia, estamos viviendo la proliferación de múltiples propuestas acerca del diseño de sistemas educativos o sobre estrategias de enseñanza-aprendizaje en el aula sin que se observe claramente la respuesta a una pregunta clave para cualquier educador: ¿por qué tipo de sociedad apostamos?, ¿qué modelo de persona es el que queremos formar? Interrogante básico, esencial, al que tiene que subordinarse cualquier proyecto educativo. Dicha pregunta, a nuestro entender, podría contestarse de manera satisfactoria a partir de una teoría de la justicia, incluida dentro del "enfoque de las capacidades», que es la postulada por Martha Nussbaum, Premio Príncipe de Asturias de Ciencias Sociales en el 2012. Una teoría que, entre otras cosas, va a cuestionar ese término tan querido en la Modernidad como el de "progreso" y que ha ido derivando en rumbos que han descuidado el papel esencial que juega la persona y su dignidad como ser humano. A partir de ahí, mostraremos 
el tipo de educación necesaria para crear una sociedad donde el bienestar social (el de todos y no el de unos pocos) y la felicidad del individuo se conviertan en los principales protagonistas. Una educación que podrá ser definida como crítica, reflexiva, socrática, participativa, pluralista e intercultural. Por último, a modo de epílogo, expondremos algunas reflexiones personales.

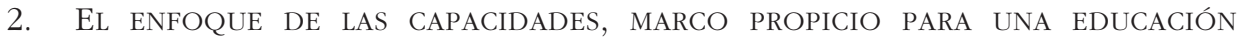 DE CALIDAD}

La teoría de la justicia defendida por Martha Nussbaum, en obras como Las fronteras de la justicia (2005; ed. esp. 2007) o Crear capacidades. Propuestas para el desarrollo bumano (2012), se inserta dentro de un paradigma teórico en el campo del desarrollo y de las políticas públicas conocido por diversos nombres: "enfoque del desarrollo humano", "enfoque de las capacidades» o "enfoque de la capacidad». Dicho paradigma se propone como alternativa al que ha sido y es hegemónico, aquel que se ampara en la idea de que la calidad de vida de un país mejora sólo cuando se incrementa su producto interior bruto (PIB). Este indicador indiferenciado asigna notas elevadas a países con grandísimas desigualdades, naciones en las que un porcentaje considerable de la población no goza de los frutos de la mejora del conjunto de la economía nacional. Dado que los países reaccionan a estas calificaciones públicas que afectan a su reputación internacional, este enfoque los alienta a centrar todos sus esfuerzos en el crecimiento económico, sin prestar atención al nivel de vida de sus habitantes más pobres y sin abordar tampoco cuestiones como la salud y la educación, que normalmente no mejoran con el crecimiento económico sin más. Este modelo sigue todavía vigente y se continúa acudiendo a él para reflexionar sobre la situación de las naciones ricas y sobre lo que significa para éstas «desarrollarse» o mejorar su calidad de vida, pero donde más se aplica es en los análisis convencionales del rendimiento de los "países en vías de desarrollo» ${ }^{1}$.

Frente a este modelo, se alza el enfoque del desarrollo humano o enfoque de las capacidades que ha tenido una repercusión creciente en las organizaciones internacionales que tratan y debaten cuestiones relacionadas con el bienestar humano, desde el Banco Mundial hasta el Programa de las Naciones Unidas para el Desarrollo (PNUD). Es un paradigma que parte de las preguntas: ¿qué son realmente capaces de hacer y de ser las personas?, ¿y qué oportunidades tienen verdaderamente a su disposición para hacer o ser lo que puedan? Esta pregunta es compleja porque la calidad de una vida humana implica múltiples elementos cuya interrelación precisa de un estudio determinado.

1. Anualmente, el Banco Mundial saca una lista de todos los países del mundo ordenados por su producto interior bruto. Por ejemplo, en la edición de 2012, encabezaba el ranking Estados Unidos, seguido de China, Japón, Alemania y Francia. Fuente: «http://www.worldbank.org/». 
Lo que se pone en cuestión es la visión del "progreso", de "riqueza» o de "desarrollo» que ha ido degenerándose hasta entenderse como incremento del PIB de un Estado -sea nacional o transnacional, como la Unión Europea-. La auténtica riqueza o progreso de un país sólo puede plantearse centrando la mirada en el bienestar que poseen los individuos concretos de dicho Estado, revisando si existe justicia social, si todos y cada uno de los sujetos gozan de unos mínimos de calidad de vida, si no se limitan a sobrevivir, sino que disfrutan de lo que podríamos llamar

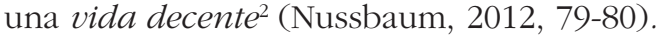

En ese paradigma, como pilar central, se halla como fundamento una teoría de la justicia, una teoría que pone énfasis en una lista de las capacidades que parece razonable suponer que componen las condiciones mínimas de una vida digna con carácter universal: la vida misma; la salud física; la integridad corporal; los sentidos, la imaginación y el pensamiento; las emociones; la razón práctica; la adscripción social o afiliación; la relación con la naturaleza ("otras especies»); el juego y el control sobre el propio medio. Ésta sería la descripción de dichas capacidades según la propia Martha Nussbaum:

1. Vida. Poder vivir hasta el término de una vida humana de una duración normal; no morir de forma prematura o antes de que la propia vida se vea tan reducida que no merezca la pena vivirla. 2. Salud física. Poder mantener una buena salud, incluida la salud reproductiva; recibir una alimentación adecuada; disponer de un lugar adecuado para vivir. 3. Integridad física. Poder moverse libremente de un lugar a otro; estar protegido de los asaltos violentos, incluidos los asaltos sexuales y la violencia doméstica; disponer de oportunidades para la satisfacción sexual y para la elección en cuestiones reproductivas. 4. Sentidos, imaginación y pensamiento. Poder usar los sentidos, la imaginación, el pensamiento y el razonamiento, y hacerlo de un modo "auténticamente humano", un modo que se cultiva y se configura a través de una educación adecuada, lo cual incluye la alfabetización y la formación matemática y científica básica, aunque en modo alguno se agota en ello. Poder usar la imaginación y el pensamiento para la experimentación y la producción de obras y eventos religiosos, literarios, musicales, etc., según la propia elección. Poder usar la propia mente en condiciones protegidas por las garantías de la libertad de expresión tanto en el terreno político como en el artístico, así como de la libertad de prácticas religiosas. Poder disfrutar de experiencias placenteras y evitar los dolores no beneficiosos. 5. Emociones. Poder mantener relaciones afectivas con personas y objetos distintos a nosotros mismos; poder amar a aquellos que nos aman y se preocupan por nosotros, y dolernos por su ausencia; en general, poder amar, penar, experimentar ansia, gratitud y enfado justificado. Que nuestro desarrollo emocional no quede bloqueado por el miedo y la ansiedad. (Defender esta capacidad supone defender formas de asociación humana de importancia

2. Preguntada Nussbaum por su concepto de decencia en una entrevista publicada en La Vanguardia en 2010, responde: "En el pasado, la decencia estaba vinculada a ciertos comportamientos sexuales. Lo indecente hoy es que una persona no pueda vivir de acuerdo con los que considera digno" (GAMPER, 2010, 3). 
crucial y demostrable para este desarrollo). 6. Razón práctica. Poder formarse una concepción del bien y reflexionar críticamente sobre los propios planes de la vida. (Esto implica una protección de la libertad de conciencia y de la observancia religiosa). 7. Afiliación. A. Poder vivir con y para los otros, reconocer y mostrar preocupación por otros seres humanos, participar en diversas formas de interacción social; ser capaz de imaginar la situación de otro. (Proteger esta capacidad implica proteger las instituciones que constituyen y promueven estas formas de afiliación, así como proteger la libertad de expresión y de asociación política); B. Que se den las bases sociales del autorrespeto y la no humillación; ser tratado como un ser dotado de dignidad e igual valor que los demás. Eso implica introducir disposiciones contrarias a la discriminación por razón de raza, sexo, orientación sexual, etnia, casta, religión y origen nacional. 8. Otras especies. Poder vivir una relación próxima y respetuosa con los animales, las plantas y el mundo natural. 9. Juego. Poder reír, jugar y disfrutar de actividades recreativas. 10. Control sobre el propio entorno. A. Político. Poder participar de forma efectiva en las elecciones políticas que gobiernan la propia vida; tener derecho a la participación política y a la protección de la libertad de expresión y de asociación. B. Material. Poder disponer de propiedades (ya sean bienes mobiliarios o inmobiliarios), y ostentar los derechos de propiedad en un plano de igualdad con los demás; tener derechos a buscar trabajo en un plano de igualdad con los demás; no sufrir persecuciones y detenciones sin garantías. En el trabajo, poder trabajar como un ser humano, ejercer la razón práctica y entrar en relaciones valiosas de reconocimiento mutuo con los demás trabajadores (Nussbaum, 2007, 88 y 89).

Las capacidades -dice la autora- no son simples habilidades residentes en el interior de una persona, sino que incluyen también las libertades o las oportunidades creadas por la combinación entre esas facultades personales y el entorno político, social y económico (Nussbaum, 2012, 40)ํ․ Según declara Nussbaum, la idea intuitiva básica de su enfoque de las capacidades es que debemos partir de una concepción de la dignidad del ser humano y de una vida acorde con esa dignidad. Las capacidades se entienden como requisitos mínimos básicos para una existencia digna y formarían parte de una teoría mínima de la justicia social: una sociedad que no las garantice a toda su ciudadanía, en un nivel mínimo adecuado, no llega a ser una sociedad plenamente justa, sea cual sea su grado de opulencia.

El reverso de las capacidades sería el funcionamiento, entendido como la realización activa de una o más capacidades; son los productos o materializaciones de

3. Podríamos relacionar el término "capacidades» en el sentido que le otorga Nussbaum con el de "competencia", actualmente muy empleado en nuestro campo educativo de "competencia". Autores como BISQUERRA y PÉREZ (2007) la definen como la "capacidad para movilizar adecuadamente un conjunto de conocimientos, capacidades, habilidades y actitudes necesarias para realizar actividades diversas con un cierto nivel de calidad y eficacia". Ambos señalan que las competencias se desarrollan a lo largo de toda la vida y siempre se pueden mejorar, y que se puede manifestar una competencia en un área concreta en un contexto dado y no manifestarla en otro contexto diferente. Esta última aclaración asemeja aún más el concepto de competencia de ambos autores al de Nussbaum puesto que se liga a la importancia concedida por la estadounidense al entorno donde se desenvuelve el sujeto. 
unas capacidades (ibídem, 44). Hay una conexión estrecha entre capacidad y libertad: podríamos decir que capacidad significa "oportunidad de seleccionar", "libertad de elección». Por usar un ejemplo de Amartya Sen, Premio Nobel de Economía en 1998, y arduo defensor del enfoque de las capacidades, una persona que pasa hambre y otra que ayuna tienen el mismo funcionamiento en lo que a su nutrición respecta, pero no disponen de la misma capacidad, pues la que ayuna es capaz de no hacerlo, mientras que la hambrienta no tiene elección.

Nussbaum declara su preferencia por situar las capacidades como objetivos políticos y no los funcionamientos en función de su liberalismo político y, por consiguiente, su respeto al pluralismo. Señala -creemos que con razón- que son las capacidades las que garantizan la existencia de un espacio para el ejercicio de la libertad humana. Existe, por ejemplo, una diferencia moral enorme entre una política que promueve la salud y otra que promueve las capacidades en materia de salud: la segunda (y no la primera) es la que verdaderamente respeta la elección de estilo de vida de la persona (ibídem, 45).

Nos parece de especial atractivo en esta teoría el énfasis en la persona como ser individual. Nussbaum predica que "las capacidades pertenecen, en primer y prioritario lugar, a las personas individuales, y sólo luego, en sentido derivado, a los colectivos. El enfoque propugna un principio según el cual cada persona es un fin en sí misma. Estipula que el objetivo es producir capacidades para todas y cada una de las personas, sin usar a ninguna de ellas como medio para las capacidades de otras ni para las del conjunto» (ibídem, 55). Esto es, ningún individuo se sacrifica por la colectividad, todos son igualmente valiosos, en tanto todos están dotados de igual dignidad. Asimismo, otro aspecto muy importante cara a las sociedades pluralistas, multi y transnacionales contemporáneas es que Nussbaum señala que los países tienen cierto margen para desarrollar esas capacidades de forma diferente en función de sus distintas tradiciones e historias (ibídem, 60), es decir, se atiende en todo momento al pluralismo, a la diversidad. Y advierte de que a la hora de fijar un umbral mínimo de desarrollo de las capacidades cara a una vida decente, con cierta calidad, siempre será irrenunciable el proceso político de una democracia funcional y operativa (ibídem, 62).

Conviene añadir que, para fijar la lista de capacidades, Martha Nussbaum se vale del diálogo intercultural, esto es, mediante dicho diálogo, contrastando comunidades culturales diferentes, pretende descubrir qué capacidades son valiosas por sí mismas, forma de llegar a un consenso compartido entre personas pertenecientes a tradiciones diversas al estilo de Rawls (1971, 1993). Además, en ningún momento esta lista de capacidades se debe tomar como algo cerrado, no sujeto a revisión, sino todo lo contrario, es susceptible de revisiones periódicas y de nuevas incorporaciones. Ésta es la razón de que sea requisito bajo esta teoría normativa

4. Hay que matizar que Nussbaum indica que, en el caso de los niños, nos encontraríamos ante una situación distinta: "Exigirles ciertas formas de funcionamiento (como, por ejemplo, la educación obligatoria) es defendible como preludio necesario de la capacidad adulta» (NussBaum, 2012, 46). 
el mantener vivo el diálogo y el debate entre las distintas culturas en torno a las capacidades valiosas por sí mismas.

Si acogemos esta teoría de la justicia, y en general el enfoque de las capacidades, como aquello que nos pueda servir de guía para el diseño de una sociedad mejor $^{5}$, y por tanto de la educación que debemos proponer -que además recoge nuestra mejor tradición occidental, nuestro más valioso legado a la Humanidad, como es la reivindicación de ciertos derechos humanos que consideramos universalizables, y que contiene en sí la esencia de la democracia, la apuesta por unos valores y por un ciudadano responsable y constructor del espacio político que habita-, entonces hemos de ser conscientes de que tenemos el deber de reclamar y apelar a las instituciones políticas para que promuevan la capacitación de los ciudadanos/as encaminada a poder gozar de una buena vida humana; debemos interiorizar que es nuestra obligación denunciar aquellas situaciones en las que determinadas instituciones, sean políticas, económicas o sociales, violan la promoción de tal capacitación, y por tanto impiden alcanzar la justicia social. Hemos de asumir que somos ciudadanos activos que, conscientes de su dimensión política, estamos impelidos a luchar por garantizar una vida más justa y humana para todas las personas; en primer lugar, en nuestro espacio europeo; pero con miras a su extensión por todo el planeta.

Asociado a este enfoque de las capacidades, derivado de él, Martha Nussbaum propone un cierto tipo de educación, una determinada pedagogía, que puede ser caracterizada como socrática -por su interés en la reflexión personal, en el examen de uno mismo, por el enorme peso del diálogo...- y pluralista - por su apuesta por unos valores básicos, no reductibles unos a otros e inconmensurables, y por su respeto a diversos estilos de vida-.

5. En el libro Emociones políticas (2014), Nussbaum explicita claramente el modelo de sociedad por el que apuesta, al que llama «aspiracional» (y que se correspondería con aquellas que deberían existir en los países que a sí mismos se denominan «democráticos», cuya máxima inquietud tendría que ser conseguir la justicia social) dentro de la línea del liberalismo político. Esto es, se trata de una sociedad donde «los principios políticos no deben erigirse sobre ninguna doctrina comprehensiva concreta, ni religiosa ni laica, del sentido y el propósito de la vida y, como corolario que se desprende del principio de la igualdad de respeto por todas las personas, todo patrocinio gubernamental de una visión religiosa o ética comprehensiva en particular debe estar escrupulosamente restringido» (NussBaum, 2014, 19). Los principios políticos han de ser tales que pueden ser objeto de un "consenso entrecruzado" entre todos los ciudadanos que respeten a los demás como sus iguales y estén dispuestos a acatar unos términos equitativos de cooperación. Como características de este modelo, la filósofa norteamericana señala una serie de valores centrales, como la consideración de la persona como fin en sí misma, la idea de igual valor entre todos los seres humanos, la prominencia moral de la soberanía nacional, la igualdad de libertades políticas y civiles para todos los ciudadanos, el compromiso radical con la calidad en la educación y en la salud, la libertad religiosa amplia, y el fomento de la crítica y el debate (ibídem, 145 y ss.). 


\section{LA PEDAGOGÍA SOCRÁtica Y PLURALISTA DE MARTHA NuSSBAum}

Martha Nussbaum es todavía una desconocida para muchos educadores ${ }^{6}$. Su procedencia del ámbito filosófico quizá ha determinado esta situación ${ }^{7}$. Sin embargo, al igual que otros autores norteamericanos como John Dewey o Sidney Hook, ella siempre ha insistido en que la filosofía debe bajar a la arena pública, tiene que ocuparse de los problemas de los hombres y mujeres, tal como escribió Dewey en Reconstruction of Philosophy (1920) ${ }^{8}$. Para Nussbaum, la filosofía, además de ser rigurosa, debe ser "util» y los filósofos/as han de ser "defensores de la humanidad", como reclamaba Sócrates, su autor favorito (Boynton, 1999). Esta preocupación le ha llevado a dedicar varios de sus trabajos al campo de la educación, obras como Cultivating Humanity: A Classical Defense of Reform in Liberal Education (1997) o Not for Profit: Why Democracy Needs the Humanities (2010), que exigen un profundo cambio en las políticas educativas desarrolladas por los diferentes países occidentales y en los objetivos y estrategias de enseñanzaaprendizaje que se persiguen en la mayoría de nuestras aulas.

Nussbaum parte de lo que ella considera una crisis de proporciones gigantescas y de enorme gravedad a nivel mundial puesto que lo que está en juego es ese bien que llamamos democracia: la crisis en materia de educación. Escribe, procurando hacernos conscientes del riesgo que corremos, que

sedientos de dinero, los estados nacionales y sus sistemas de educación están descartando sin advertirlo ciertas aptitudes que son necesarias para mantener viva a la democracia. Si esta tendencia se prolonga, las naciones de todo el mundo en breve producirán generaciones enteras de máquinas utilitarias, en lugar de ciudadanos cabales con la capacidad de pensar para sí mismos, poseer una mirada crítica sobre las tradiciones y comprender la importancia de los logros y los sufrimientos ajenos (Nussbaum, 2010, 19-20).

Es decir, la norteamericana nos advierte de que se está descuidando lo que ella considera más propio del ser humano: la formación para el pensamiento reflexivo,

6. Ya se encuentran algunos trabajos referidos a sus propuestas educativas como los de BENÉITEZ (2009 y 2010), VilaFranca y BuXARRAis (2009) y Guichot (2013), entre otros.

7. Martha Craven Nussbaum (nacida en 1947) estudió teatro y lenguas clásicas en la Universidad de Nueva York (NYU) (Bachelor of Arts, 1969), y posteriormente se fue acercando a la filosofía, hasta que se doctoró en dicha especialidad en Harvard en 1972. Ha impartido clases de filosofía, concretamente en el campo de la filosofía moral y política, en Harvard, Brown, Oxford y Chicago. En el discurso que pronunció en octubre de 2012 al recibir el Premio Príncipe de Asturias de Ciencias Sociales, ella misma se definió como «una filósofa que ha trabajado no solo en la filosofía política, sino también en la naturaleza de las emociones y de la imaginación y en el problema de la interdependencia y vulnerabilidad humanas, a menudo recurriendo a obras literarias y musicales para dilucidar estas cuestiones» (se puede acceder al discurso completo en la página web de la Fundación Príncipe de Asturias <www.fpa.es>).

8. Queremos recordar que Dewey considera que la filosofía podría definirse como la teoría general de la educación, puesto que la educación debería considerarse como un proceso en la búsqueda de lograr unas disposiciones fundamentales, intelectuales y emocionales (DEWEY, 1938, 58). 
crítico, original; la empatía, la compasión y la solidaridad hacia los otros ; la educación, en definitiva, para la libertad.

Si hablamos de educación (en y) para la libertad, es necesario aclarar los términos. La reivindicación de una educación liberal de Nussbaum poco o nada tiene que ver con las últimas apuestas neoliberales que estamos viviendo -o sufriendo-. Siguiendo a sus admirados filósofos estoicos, especialmente a Séneca, entiende educación liberal como aquella auténticamente adecuada para la libertad y ésta es definida:

Una educación es verdaderamente "adecuada para la libertad" solo si produce ciudadanos libres, ciudadanos que son libres no debido a la riqueza o al nacimiento, sino porque se saben dueños de sus propias mentes. Hombres y mujeres, nacidos esclavos y nacidos libres, ricos y pobres, se han mirado a sí mismos y han desarrollado la habilidad de distinguir entre el mero hábito y la convención, y lo que pueden defender con argumentos. Son dueños de su propio pensamiento y voz, y esto les confiere una dignidad que está mucho más allá de la dignidad exterior de clase y rango (Nussbaum, 2001, 327).

La educación liberal se enlaza con el concepto de ciudadanía, ya que su propósito es el de crear ciudadanos y ciudadanas libres. En la terminología de Nussbaum, su fin es posibilitar que las personas posean ciertas capacidades que les faciliten una vida digna, decente, "feliz". Entre ellas, destaca la de promover que los seres humanos "sean dueños de su propio pensamiento y voz", esto es, sean reflexivos y críticos, que es para ella la característica que mejor describe lo que nombra como «educación socrática». Junto a ésta, Nussbaum coloca capacidades básicas teniendo en cuenta la sociedad pluralista en que vivimos -la diversidad

9. La filósofa estadounidense otorga un papel de primer orden al cultivo a través de la educación de las denominadas «emociones públicas»-aquellas que tienen como objeto la nación y otros espacios políticos ligados al sujeto, sus objetivos, instituciones y dirigentes, su geografía, y la percepción de los conciudadanos como habitantes con los que se comparte un espacio público común (NussBaum, 2014, 14). Bajo la tesis de que «todos los principios políticos [...] precisan para su materialización y su supervivencia de un apoyo emocional que les procure estabilidad a lo largo del tiempo, y todas las sociedades decentes (decent) tienen que protegerse frente a la división y la jerarquización cultivando sentimientos apropiados de simpatía y amor» (ibídem, 15), defiende que la sociedad justa a la que se debe aspirar tiene dos misiones fundamentales: cultivar emociones que ayuden al sostenimiento del compromiso con proyectos valiosos que requieran de esfuerzo y sacrificio; y mantener bajo control ciertas emociones negativas como la envidia, el asco hacia ciertos grupos sociales por razón de etnia, religión, etc., que ponen en peligro la cohesión social. El papel de la educación es crucial: «La educación es un objetivo, pero también supone una oportunidad. Cuando la sociedad adopta un compromiso con la educación, se compromete también con su propia estabilidad futura, no sólo en el aspecto económico, sino también en lo relacionado con la búsqueda de la materialización de sus objetivos políticos. La educación será, pues, uno de los principales terrenos en los que tendrá lugar la conformación de una simpatía políticamente apropiada, y en los que se desalentará la adopción de formas inapropiadas de odio, asco y vergüenza» (ibídem, 154). 
de formas de pensar, de sentir, de ser, que nos rodea- ${ }^{10}$, junto con la necesidad de trascender las lealtades nacionales y de afrontar los problemas internacionales como ciudadanos del mundo: la empatía, la tolerancia, la criticidad, la imaginación narrativa, el entendimiento de las historias y las contribuciones de los grupos con los que interactuamos, etc.

No es difícil observar que Nussbaum opera con un concepto de democracia muy parecido al de su admirado -y continuamente nombrado- John Dewey: democracia como un estilo de vida, como una forma de afrontar la existencia, que se basa en una serie de valores (libertad, respecto activo hacia el otro, solidaridad, justicia social, etc.) (Guichot, 2013, 187). Dichos valores subyacen en la lista de capacidades que presentamos más arriba y concuerdan con los latentes en los que conocemos como Derechos Humanos ${ }^{11}$. Ambos enfoques, el denominado "de las capacidades» y el movimiento internacional en defensa de los derechos humanos, coinciden en torno a la idea de que todas las personas tienen derecho a unos bienes centrales en virtud de su humanidad misma (protegidos incluso de la decisión de las mayorías) y que uno de los deberes fundamentales de la humanidad es el de respetar y apoyar tales derechos (Nussbaum, 2012, 83). El Estado que se plantee sinceramente promoverlos ha de imponerse como misión el fomento de aptitudes fundamentales como:

- La aptitud para reflexionar sobre las cuestiones políticas que afectan a la nación, analizarlas, examinarlas, argumentarlas y debatirlas sin deferencia alguna ante la autoridad o la tradición.

- La aptitud para reconocer a los otros ciudadanos como personas con los mismos derechos que uno, aunque sean de distinta raza, religión, género y orientación sexual, y de contemplarlos con respeto, como fines en sí mismos y no como medios para obtener beneficios propios mediante su manipulación.

- La aptitud para interesarse por la vida de los otros, de entender las consecuencias que cada política implica para las oportunidades y las experiencias de los demás ciudadanos y de las personas que viven en otras naciones.

- La aptitud para imaginar una variedad de cuestiones complejas que afectan a la rama de una vida humana en su desarrollo y de reflexionar sobre la infancia, la adolescencia, las relaciones familiares, la enfermedad y la muerte y muchos otros temas, fundándose en el conocimiento de todo un abanico de historias concebidas como más que un simple conjunto de datos.

- La aptitud para emitir un juicio crítico sobre los dirigentes políticos, pero con una idea realista y fundada en las posibilidades concretas que éstos tienen a su alcance.

10. Nussbaum escribe que en nuestro complejo mundo «la indagación socrática impone el pluralismo» (Nussbaum, 2001, 58).

11. Nussbaum considera el enfoque de las capacidades como una subespecie del enfoque de los derechos humanos. Para una extensa argumentación de dicha afirmación se puede consultar: NussBAUM, 2012, 83-126. 
- La aptitud para pensar en el bien común de la nación como un todo, no como un grupo reducido a los propios vínculos locales.

- La aptitud para concebir a la propia nación como parte de un orden mundial complejo en el que distintos tipos de cuestiones requieren de una deliberación transnacional inteligente para su solución (Nussbaum, 2010, 48-49).

Esto es, Nussbaum está hablando de la necesidad por parte de los Estados de promover una educación para la ciudadanía que podría ser definida como la "formación integral de la persona que, capaz de interpretar y adaptarse críticamente a su realidad, y de transformarla en una línea optimizadora, ejerce su ciudadanía de forma activa e intercultural y asume diferentes ámbitos de pertenencia en los que desarrolla su dimensión política» (Guichot, 2012, 40; Guichot, 2013, 187). Una educación para una ciudadanía que debería caracterizarse como activa, porque una democracia robusta reclama un ciudadano/a comprometido/a con la deliberación en la toma de decisiones que afecta a la cosa pública; compleja o múltiple, dado que hemos de compaginar y armonizar nuestra intervención y vivencia política en varios espacios, que van desde el ámbito local al cosmopolita; e intercultural, debido a que el respeto y el reconocimiento mutuo ha de ser la base para la convivencia (Feinberg, 1998; Cortina, 1998; Bartolomé y Cabrera, 2003; Rubio Carracedo, 2000).

Como señalamos más arriba, Nussbaum reivindica tres metas esenciales en la educación liberal: el examen crítico de uno mismo, el ideal de ciudadano del mundo ${ }^{12}$ y el desarrollo de la imaginación narrativa, entendida como "la capacidad de pensar cómo sería estar en el lugar de otra persona: ser un lector inteligente de la historia de esa persona, y comprender las emociones, deseos y anhelos que alguien así pudiera experimentar» (Nussbaum, 2001, 30). Dichos fines permitirían "cultivar la humanidad», que sería sinónimo a posibilitar el pleno desarrollo de nuestra dignidad humana. Nos ocuparemos de desglosar cómo deberían de reflejarse en la educación cada uno de ellos.

12. Martha Nussbaum señala dos formas de entender ese "ser ciudadano del mundo", aunque en su obra desarrolla especialmente la segunda opción. Suyo es este párrafo: "El ideal clásico del "ciudadano del mundo" se puede entender de dos maneras, e igualmente el "cultivo de la humanidad". La versión más inflexible y exigente es el ideal de un ciudadano cuya lealtad principal es para con los seres humanos de todo el mundo, y cuyas otras lealtades nacionales, locales y de grupos diversos se consideran claramente secundarias. Su versión más blanda permite una diversidad de visiones sobre cuáles deberían ser nuestras prioridades, pero nos dice que, sin importar cómo ordenemos nuestras lealtades, siempre deberíamos estar seguros de reconocer el valor de la vida humana en cualquier lugar que se manifieste, y de vernos a nosotros mismos como ligados por capacidades y problemas humanos comunes con las personas que se hallan a gran distancia de nosotros. Estas dos versiones han existido al menos desde la Roma antigua, cuando el estadista y filósofo Cicerón suavizó las estrictas exigencias del estoicismo griego para el público romano. Aunque simpatizo con la tesis más estricta, es la tesis más blanda e inclusiva la que trataré [...]»(Nussbaum, 2001, 28-29). 


\subsection{La pedagogía socrática: la importancia de la argumentación}

Nussbaum señala la necesidad de poseer la habilidad para un examen crítico de uno mismo y de las propias tradiciones que nos permita experimentar lo que, siguiendo a Sócrates, podríamos llamar «vida examinada». Ésta es definida como «una vida que no acepta la autoridad de ninguna creencia solo por el hecho de que haya sido transmitida por la tradición o se haya hecho familiar a través de la costumbre; una vida que cuestiona todas las creencias y solo acepta aquellas que sobreviven a lo que la razón exige en cuanto a coherencia y justificación (ibídem, 29). Esta disciplina requiere el desarrollo de la habilidad de razonar lógicamente, de poner a prueba lo que uno lee o dice desde el punto de vista de la solidez del razonamiento, de la exactitud de los hechos y la precisión de juicio.

Resulta interesante observar la relación que establece Sócrates entre la capacidad del examen de sí mismo y la democracia, que la propia Nussbaum comenta en su libro El cultivo de la humanidad (2001). Señala esta filósofa que Sócrates prefiere la democracia a otras formas de gobierno porque es noble debido a que reconoce y respeta los poderes de deliberación y de elección que todos los ciudadanos comparten ${ }^{13}$. En esta línea, sostiene que los atributos necesarios para llegar a ser un buen ciudadano pensante se encuentran en todos los ciudadanos, o por lo menos en todos los que no están en algún grado importante privados de la normal capacidad de razonar. A diferencia de su discípulo Platón, quien defiende que un posible juez y legislador requiere de un alto nivel de experiencia matemática y científica, Sócrates sólo pide que el juez posea el tipo de capacidad moral que la gente común posee y usa en su proceder cotidiano. Su principal preocupación es que esta capacidad sea educada y aguzada para hacerla más plena (ibídem, 37-40). Así, Sócrates insiste en que la educación progresa, no por el adoctrinamiento del profesor, sino por el escrutinio crítico de las propias creencias del alumno.

La idea socrática de que para un ser humano no vale la pena vivir la vida sin examen ${ }^{14}$ conlleva la necesidad de que se proporcione a todas las personas. Si los encargados de hacerlo son, a nivel profesional, maestros/as y profesores/ as, habrá que hacer especial hincapié en que proporcionen una enseñanza estimulante e incisiva, capaz de despertar la mente; una enseñanza que «aguijonee»

13. Escribe J. J. Benéitez que Nussbaum ha recibido bastantes críticas en el sentido de que el tipo de ciudadanía socrática que propone se parece realmente a la que se concibe en el corpus aristotélico (sobre todo en las Éticas eudemia y nicomáquea, pero también en el libro i de la Política y a lo largo de la Retórica), puesto que fue Aristóteles quien articuló las capacidades del ciudadano u hombre prudente (phronimos) y no tanto a la de Sócrates -al que conocemos sobre todo por Platón-. A la vista de las explicaciones que ella misma hace en El cultivo de la humanidad, el concepto de educación socrática responde, mejor, a la recepción de la imagen y pensamiento de Sócrates en el estoicismo y, a su vez, al eco que éste tuvo en el pensamiento de la ilustración del siglo XviII con Adam Smith, Kant o, más concretamente, con las reflexiones que hicieron los Padres Fundadores en los EE. Uu. (vd. en BENÉITEZ, 2009, 409).

14. Es bien sabido que Sócrates no dejó nada escrito. La sentencia de que una vida sin examen no merece la pena ser vivida ser halla en la Apología de Sócrates, escrita por su discípulo Platón (38a5-6). 
el pensamiento de los alumnos y alumnas y que se aleje de la enseñanza pasiva, memorística, "bancaria" -como la llama Paulo Freire (1978)-, donde el discente es visto como una especie de vasija vacía donde depositar los contenidos transmitidos por el profesor.

Nussbaum indica que, aunque todas estas habilidades vinculadas al examen de uno mismo y de los demás deben trabajarse transversalmente, es conveniente, especialmente en la enseñanza superior, que algún curso se enfoque de manera intensiva en la argumentación crítica. En este sentido, señala la conveniencia de un curso o cursos de filosofía, puesto que considera que el filósofo profesional es (debería ser) experto en el arte de analizar los argumentos propios y los de otros. La filosofía que propone estaría centrada en intereses humanos básicos: temas relacionados con la justicia y los derechos; con el amor, el miedo y el dolor; con la ética médica, legal y comercial... ${ }^{15}$. Asimismo, Nussbaum señala algunas condiciones que tendrían que respetarse como el tamaño de la clase -unos veinte alumnos/ as máximo es lo ideal (Nussbaum, 2001, 70)-, cuidar una actitud de respeto entre todos los estudiantes, estimular la participación activa, huir de los exámenes estandarizados ${ }^{16}$, etc. Sería importante mostrar a los estudiantes lo estrechas y limitadas que pueden ser sus propias perspectivas e invitarles a practicar la reflexión crítica, a romper con la comodidad de las verdades aseguradas. Suyas son las siguientes palabras referidas a la enseñanza en el nivel terciario y universitario:

Cabe preguntarse [...] de qué manera específica se pueden transmitir los valores socráticos mediante la educación humanística. A nivel terciario y universitario, la respuesta es bastante comprensible. Como punto de partida, se debería incorporar el pensamiento crítico a la metodología pedagógica de distintos cursos, enseñando a los estudiantes a indagar, a evaluar las pruebas, a escribir sus propios trabajos con argumentos bien estructurados y a analizar los argumentos que exponen en otros textos (Nussbaum, 2010, 84).

Tal como la filósofa norteamericana nos recuerda, no hay que olvidar que nadie, ni siquiera el más inteligente, es capaz de desglosar un argumento sin

15. Nussbaum recomienda que estos cursos sean obligatorios, porque observa que la filosofía suele ser intimidante para los estudiantes, que piensan que es para una élite. La exigencia de estos cursos de Filosofía podría hacerse de varias formas: "Una podría ser que se exigiera directamente un curso de filosofía, ya sea escogido dentro del currículo fijo del departamento o entre un grupo distinto de cursos introductorios. Se podría, como se hace en Harvard, exigir un curso sobre "razonamiento moral", que reúne a los docentes de distintas disciplinas en una misión común. También se podría incentivar el razonamiento y el análisis filosófico en un curso básico de humanidades, como, por ejemplo, uno dedicado a la lectura de distintos textos filosóficos importantes. La base disciplinaria de tales cursos no debería desviarse demasiado de la filosofía, o se debilitaría el rigor del análisis, tan importante para las virtudes socráticas de la mente» (Nussbaum, 2001, 69).

16. «Los exámenes estandarizados no son muy útiles para evaluar esa capacidad socrática. Haría falta una evaluación cualitativa mucho más detallada de las interacciones en el aula y los escritos del alumno para saber en qué medida ha adquirido la capacidad de argumentación crítica» (NussBAum, 2010, 76). 
que alguien le haya enseñado a hacerlo: las capacidades de deliberación, de argumentación deben ser aprendidas. Por ello, en una época como la nuestra, Nussbaum subraya que los estudiantes necesitan que se haga hincapié en ellas, con el fin de desarrollar de un modo más completo su competencia para el ejercicio de la ciudadanía y la interacción política respetuosa (ibídem, 85).

\subsection{Educación para la ciudadanía mundial}

Una de las características de nuestro momento histórico es que, por primera vez, vivimos en una sociedad de carácter planetario. Las tradicionales fronteras nacionales que encerraban la vida social dentro de los parámetros del Estadonación han disminuido su poder de separar a las sociedades y nos hallamos ante un avance creciente de la denominada «sociedad globalizada». Se trata de un movimiento heterogéneo y asimétrico, pero ello no impide la posibilidad de hablar de la "conciencia y el sentimiento de patria-tierra", como señalaba Edgar Morin, o simplemente de conciencia de globalidad ${ }^{17}$. El sistema económico mundial y la omnipresencia de las nuevas tecnologías de la comunicación, como dos principales factores, nos han enfrentado a nuestra común humanidad y a los límites de un mundo que reclama emprender acciones colectivas con «intencionalidad cosmopolita». Y no sólo para evitar el daño a determinados bienes públicos planetarios, como la preservación del medio ambiente o la elusión de guerras o catástrofes de gran envergadura, sino para acercarse a lo que podríamos llamar una ciudadanía mundial o cosmopolita.

¿Qué implica esa ciudadanía cosmopolita? Martha Nussbaum la concibe como aquella que sostiene que nuestra principal lealtad debe ser con el común de la humanidad y los primeros principios de nuestro pensamiento práctico deben respetar el igual valor de todos los miembros de la comunidad (Nussbaum, 1999). La perspectiva cosmopolita no es una invención reciente dentro de la filosofía, aunque la globalización actual la ha sacado a la palestra. Ya fue acogida por los estoicos quienes, además, aclaraban que para ser ciudadano del mundo uno no debía renunciar a sus identificaciones locales. Sugerían que pensásemos en nosotros mismos no como seres carentes de filiaciones locales, sino como seres rodeados de una serie de círculos concéntricos. El primero de estos círculos rodearía el yo; el segundo, la familia inmediata, y a éste le seguiría el de la familia extensa. A continuación, y por orden, el vecindario o los grupos locales; los conciudadanos y los compatriotas -y a esta lista se podrían fácilmente añadir otros grupos

17. «La globalización es, a la vez, un proceso objetivo de comprensión del mundo en su globalidad y un proceso subjetivo de intensificación de la toma de conciencia de mundo como un todo. Por globalización se entiende un aumento de la interdependencia global que va en paralelo con la conciencia de esa interdependencia. Lo que la caracteriza de un modo esencial es, en realidad, la aparición y la difusión de una conciencia individual de la situación global y del mundo como escenario en el que todos participamos» (ROBERTSON, 1992, 8). 
basados en identidades étnicas, lingüísticas, históricas, profesionales, de género o sexuales-. Alrededor de todos estos círculos se hallaría el mayor de ellos, el de la humanidad entera. Para estoicos como Hierocles -siglos I y II de nuestra era- nuestra tarea, como ciudadanos del mundo, consistiría en «atraer, de alguna manera, estos círculos hasta el centro", haciendo que todos los seres humanos nos fuesen tan familiares como nuestros conciudadanos, y así sucesivamente. No deberíamos abandonar nuestros afectos e identificaciones particulares ya fueran éstas de tipo étnico, religioso o basadas en el género, ni sería necesario que pensáramos en ellas como algo superficial, puesto que, en parte, constituirían nuestra identidad. Pero, al mismo tiempo, también habríamos de trabajar para hacer que todos los seres humanos formasen parte de nuestra comunidad de diálogo y fuesen de nuestra incumbencia; basar nuestras deliberaciones políticas en esta comunalidad [sic] entrelazada y conferir una atención y un respeto especial al círculo que definiría nuestra humanidad ${ }^{18}$ (ibídem, 19-20).

¿Cómo debería concebirse la educación para la ciudadanía mundial? La propia Nussbaum admite que es un tema amplio y complejo que requiere el manejo de múltiples disciplinas. Como mínimo, los aportes de la historia, la geografía, el estudio interdisciplinario de la cultura, la historia de los sistemas jurídicos y políticos y el estudio de la religión; todo ello en mutua interacción y complejidad creciente conforme va aumentando la madurez de los alumnos (Nussbaum, 2010, 122).

La educación humanística es clave para la ciudadanía mundial, es su punto de apoyo, el basamento que permite desarrollarla. Si la información que las materias de humanidades proporcionan es necesaria no es suficiente. Son básicas las capacidades que han de ir unidas a ellas: el fomento del pensamiento crítico aplicado al análisis de distintas teorías económicas, de determinados acontecimientos históricos, de diferentes alternativas sobre cómo comprender la justicia social y la convivencia pacífica entre grupos dispares; la comprensión de las complejidades de otras culturas, de otros modos de afrontar la existencia; la posibilidad de hablar cuando menos alguna lengua extranjera, que no sólo nos abre nuestro espacio de comunicación, sino que nos ayuda a percibir otras formas de fragmentar la

18. La necesidad de ese "trabajo» del que nos habla Nussbaum se debe a su defensa de que todas las emociones son "eudemónicas", esto es, evalúan el mundo desde el punto de vista de la propia persona y, por consiguiente, desde la perspectiva de la concepción (en evolución) que posee ese individuo de lo que es una vida valiosa. Por ejemplo, lloramos la pérdida de aquellos seres que nos importan, no la de los que son unos perfectos extraños para nosotros. Y comenta la pensadora americana: «El eudemonismo no es egoísmo: podemos entender que otras personas tienen un valor intrínseco. Pero las que suscitan hondas emociones en nosotros son aquellas con las que estamos conectados, por así decirlo, a través de nuestra imaginación de lo que es una vida valiosa, y que forman lo que [...] llamaré nuestro "círculo de interés" o de preocupación. Así pues, para que tanto las personas que nos son distantes como los principios abstractos lleguen a captar nuestras emociones, hay que conseguir que estas sitúen a las primeras y a los segundos en ese círculo de interés, y crear así la sensación de que en "nuestra" vida esas personas y esos acontecimientos importan porque son parte de "nosotros" mismos, de nuestro bienestar y de nuestra prosperidad”(Nussbaum, 2014, 25). 
realidad $^{19}$, etc. El alumnado, a través de esta educación, debe ser capaz de interpretar el mundo en que vive, sabiendo discriminar entre las reivindicaciones válidas y las que no lo son, pudiendo escapar de continuos intentos manipuladores que pretenden pisotear el derecho libre a decidir la mejor manera de vivir. Como dice Martha Nussbaum, hay que crear ciudadanos del mundo inteligentes:

Se podría dotar a los alumnos [de información] sin las capacidades ni las técnicas que hoy relacionamos con las disciplinas humanísticas, pero contar con un catálogo de datos sin la capacidad de evaluarlos ni de entender cómo se elabora un relato a partir de ciertas pruebas empíricas es casi tan malo como ignorar por completo esos datos. En efecto, el alumno sería incapaz de distinguir entre la verdad y los estereotipos ignorantes difundidos por los dirigentes políticos y culturales, ni tampoco podría diferenciar las reivindicaciones válidas de las inválidas. Por lo tanto, la historia mundial y los principios económicos deben enseñarse desde una perspectiva humanística y crítica para que resulten útiles en la formación de ciudadanos del mundo inteligentes. Asimismo, esa enseñanza debe acompañarse de un estudio sobre las religiones y las teorías filosóficas de la justicia. Sólo así servirán de base de los debates públicos que debemos llevar a cabo para resolver de manera cooperativa los principales problemas de la humanidad (ibídem, 130).

Y es que cuando Nussbaum habla de educar en una ciudadanía mundial inteligente, tiene en cuenta formas erróneas de llevar a cabo dicha formación. En concreto, señala cuatro actividades que irían en contra de los objetivos por los que ella misma apuesta. La primera consiste en no explicar nada sobre la historia y la cultura de algunos continentes ni sobre religiones distintas a las más extendidas en ese país. Dice la pensadora norteamericana: «¿Cómo es posible que así tengamos una conducta responsable con respecto a las políticas externas, las relaciones de comercio internacional, el medio ambiente, los derechos humanos y todos los otros asuntos que deben confrontarse con un espíritu cooperativo de modo que transcienda las fronteras nacionales?» (ibídem, 122). Asimismo, es absolutamente pernicioso explicar con un criterio que suponga la hegemonía de la nación propia sobre las otras, la idea de civilización superior, defecto en el que Occidente ha caído con frecuencia. Otro gran error que vislumbra Nussbaum, y que su teoría de la justicia dentro del enfoque de las capacidades intenta subsanar, es el de no presentar en los libros las diferencias de clase, casta y género como fuente de desigualdad social -y, por tanto de injusticia-. Por último, insiste en un apartado que cualquier educador debería tener muy en cuenta: utilizar libros o plantear una forma de enseñar donde no se muestre que los relatos históricos se construyen a base de pruebas y, por tanto, no capacitar al alumnado para seleccionar y evaluar esas pruebas. Tales

19. Nussbaum comenta que todos los alumnos deberían aprender bien al menos una lengua extranjera; observar que otro grupo de seres humanos fragmentó el mundo de manera distinta y que toda traducción es en realidad una interpretación imperfecta. Y dice: "Incluso en el caso en que la segunda lengua aprendida corresponda a una cultura relativamente familiar, la concepción de la diferencia que se adquiere al aprender otro idioma es irremplazable» (NussBaum, 2010, 126). 
libros o actitudes del profesor/a fomentan el aprendizaje de memoria, desalientan el pensamiento crítico e insinúan que existe una sola historia correcta y obvia que ninguna persona respetable podría desafiar (ibídem).

Para conseguir la formación para la ciudadanía mundial que reclama, la intelectual norteamericana propone diversas estrategias. Por ejemplo, señala que hay que estudiar el propio país concibiéndolo como plural y como parte de un mundo interconectado, es decir, hay que estimular el interés y el conocimiento por los distintos grupos que lo componen, sus diferentes historias, las diversas oportunidades que recibe cada uno...; también le parece muy oportuno que el alumno profundice al menos en una tradición ajena, porque le permite adquirir herramientas que luego podría usar en otras esferas, como la capacidad de saber ponerse en el lugar del otro para comprender las razones de lo que hace; en la enseñanza de la historia, insiste en la importancia de mostrar a los estudiantes cómo se arma el relato histórico a partir de diferentes fuentes o pruebas, además de capacitarles para evaluar una narración histórica frente a otra, etc. En suma, Martha Nussbaum apuesta por una educación que, aunque la denomine multicultural, nosotros podríamos llamarla intercultural, por la importancia que dicha autora siempre concede al diálogo entre culturas:

Una educación que responda a esas necesidades debe ser una educación multicultural, es decir, aquella que pone en contacto al estudiante con algunos hechos fundamentales de la historia y cultura de muchos grupos diferentes. Entre ellos, debería incluirse tanto los principales grupos religiosos y culturales de cada parte del mundo como las minorías étnicas, raciales, sociales y sexuales en sus propias naciones. El aprendizaje del lenguaje, la historia, los estudios religiosos y la filosofía: todas estas materias tienen alguna función que cumplir en esta empresa. La conciencia de la diferencia cultural es esencial para promover el respeto hacia el otro, verdadero sustento de todo diálogo. No existen fuentes más seguras de desprecio que la ignorancia y el sentido de la inevitable naturalidad del estilo propio de cada uno. Ninguna educación liberal puede ofrecer a los estudiantes un adecuado entendimiento de todo lo que deberían saber sobre el mundo; pero una comprensión profunda de alguna tradición desconocida, y algunos rudimentos sobre otras, bastarán para engendrar el conocimiento socrático de las propias limitaciones (Nussbaum, 2001, 101).

Esta educación para la ciudadanía universal debería comenzar -a opinión de Nussbaum- a temprana edad, desde los comienzos de la escolarización, e iría avanzando en profundidad y complejidad a medida que el individuo fuese alcanzando niveles superiores de estudios. Tiene una íntima aliada en la capacidad de la "imaginación narrativa", a la que la pensadora norteamericana le da un inmenso valor, y a la que dedicaremos el siguiente apartado. 


\subsection{El desarrollo de la imaginación narrativa}

Conectada con la formación en esa ciudadanía mundial, Martha Nussbaum muestra un fuerte interés por el desarrollo de las artes en el currículum ya que cultivan la imaginación, la empatía y las capacidades de juicio y sensibilidad, que son esenciales para la construcción de tal ciudadanía ${ }^{20}$. Si bien, hasta cierto punto, dicha afirmación se podría aplicar a todas ellas -la música, la danza, la pintura, la escultura y la arquitectura participan en la formación de nuestra capacidad de entender a la gente que nos rodea-, la filósofa estadounidense presta especial atención a la literatura como elemento esencial del currículum. El motivo es su enorme poder para representar circunstancias y poderes específicos de las personas de distintas clases y, por tanto, de mostrar cosas que podrían suceder, recurso especialmente valioso en la vida política (ibídem, 122); además de su valor para estimular la capacidad de comprender a los demás, poder adoptar su perspectiva, su visión del tema tratado, sintonizar con sus sentimientos, habilidad importante en un mundo plural como el nuestro. La literatura, pues, puede desempeñar una función cívica de primer orden.

Sin embargo, no nos sirve cualquier tipo de literatura para la formación de esos ciudadanos cosmopolitas. Uno de los requisitos importantes es que las obras destinadas a esta educación moral "perturben", hagan pensar, planteen dilemas. En este sentido, Nussbaum recuerda que la cultura griega antigua asignó enorme importancia al drama trágico porque le preocupaba la educación moral del adulto joven. Ir a presenciar una tragedia no se entendía como una "experiencia estética", si eso significa una experiencia independiente del interés cívico y político. Los festivales de tragedia del siglo quinto a. C. eran festivales cívicos durante los cuales todas las otras funciones cívicas se suspendían y todos los ciudadanos se reunían. Habitualmente los dramas fueron valorados tanto por su contenido moral y político como por sus otras características. Las tragedias familiarizaban al joven ciudadano con los sucesos negativos, desagradables, que podrían suceder en la vida humana, mucho antes de que la vida misma se encargara de hacerlo (ibídem, 131; Nussbaum, 2014, 314 y ss.). Así pues, en nuestros días, un importante deber del educador es buscar obras que favorezcan la empatía y el hacer conjeturas: algunas probablemente formarán parte del «canon» de la literatura occidental, pero también habrá que añadir textos más contemporáneos que conectaran a los estudiantes con problemáticas actuales. Unos y otros deben ser tratados con espíritu deliberante y crítico. No basta con alentar a los estudiantes a que se identifiquen empáticamente con ciertos personajes y situaciones, sino que hay que procurar que se formulen preguntas críticas sobre esa experiencia (ibídem, 139).

20. Muchos pedagogos de la Escuela Nueva entendieron el importante papel de las artes para el desarrollo personal y para una educación cívica. Dewey, por ejemplo, al que cita Nussbaum, dedicó importantes trabajos al valor de las artes en tanto elementos fundamentales para una sociedad democrática (cfr. DEWEY, 1916, 226-227). 
Nussbaum advierte que todas las sociedades poseen algún "punto ciego» en particular, algún grupo dentro o fuera de su cultura que suele ser tratado con ignorancia o necedad, y se puede entonces usar una selección de obras de arte, ya sean literarias, musicales o teatrales, para estimular la crítica de esa sandez y promover una visión más apropiada de ese "punto ciego» (Nussbaum, 2010, 145). Como afirman Vilafranca y Buxarrais -siguiendo a la pensadora norteamericana-, para que, desde las artes, se contribuya a una educación moral para la ciudadanía mundial, se tienen que buscar piezas/obras que describan las circunstancias específicas de grupos con los cuales vivimos, a los que urge comprender, cultivando el habito de ver el logro o la frustración de sus aspiraciones y deseos, dentro de un mundo social que se caracteriza por sus desigualdades institucionales ${ }^{21}$. Conocer desde dentro sus vidas, sus problemas, sus dificultades, nos ayuda a comprender su situación, sus estados de ánimo, sus costumbres, su cultura. De esta manera, se abre la posibilidad tanto de la compasión por los desfavorecidos como el juicio crítico sobre el mundo social, que es el gran reto de la educación para la ciudadanía (Vilafranca y Buxarrais, 2009, 124).

La idea de que el debate literario, mediante tertulias o conversaciones públicas, abiertas, fomenta la ciudadanía no es novedosa. En la antigua Atenas, el público debatía sobre las tragedias y daba su valoración crítica de las mismas antes de que fuesen publicadas y sometidas de nuevo a debate ya como obras literarias. Y en la Alemania de Weimar, a principios del siglo xx, se organizaban públicamente grupos de debate literario para los trabajadores como estímulo del diálogo cívico (Nussbaum, 2014, 349-350). La idea latente es que dichos debates pueden promover la implicación activa de los ciudadanos en una vital cultura crítica. Recurso parecido ofrece el cine-fórum, de gran fuerza en los inicios de la Transición española y que quizá deberíamos volver a promover en la actualidad como una buena estrategia para formar habilidades esenciales de una ciudadanía crítica.

21. Nussbaum relata el siguiente ejemplo que aclara muy bien la función de las artes para remover las mentes en busca de un compromiso por luchar contras desigualdades sociales: "Tagore se preocupaba particularmente por las mujeres, quienes eran criadas para sentir vergüenza del propio cuerpo y no poder moverlo con libertad, sobre todo en presencia de los hombres. Defensor acérrimo de la libertad y la igualdad femenina, este autor entendía que para vencer años de represión no alcanzaba con sólo decirles a las niñas que se movieran con libertad, sino que hacía falta un incentivo más eficaz, como asignarles movimientos más puntuales en una coreografía para que se desplazaran saltando por el escenario. De hecho, la cuñada de Tagore inventó la blusa que hoy en día se utiliza con el sari a raíz del pedido de éste para que diseñara una prenda con la que las mujeres pudieran moverse libremente, sin temer que el sari dejara expuesta alguna parte inadecuada de su cuerpo. Los roles que ocupaban los hombres en la danza bajo el auspicio de Tagore también representaban un desafío para ellos, y él mismo gozaba de gran prestigio como bailarín y coreógrafo, sobre todo por sus movimientos sinuosos y andróginos. En las obras coreográficas, era muy frecuente que apareciera una temática explícita dirigida a cuestiones de género, como ocurre con El reino de los naipes, [...], donde las mujeres toman la iniciativa de rechazar las tradiciones más fosilizadas» (Nussbaum, 2010, 142-143). 


\section{REFLEXIONES FINALES}

«Resulta imposible negar hoy en día que hay algo que no funciona en lo que llamamos democracia y que la esperanza que suscitó antaño no se ha cumplido» (Bassas, 2010, 11). En estos tiempos de crisis, de derrumbes de seguridades, de desplomes de certezas, cada vez parece más difícil hablar de democracia a los muchos que la asociamos con el respeto a unas libertades y derechos fundamentales, entre ellos los llamados «sociales» en los que se incluyen salud, educación y prestaciones sociales. Una palabra tan noble, tan incitadora a una acción libre y justa como "democracia» (Camps, 1997), ha devenido en un término vacío, hueco, sin significado, ante su uso indiscriminado por quienes apuestan por todo lo contrario a la idea antes enunciada ${ }^{22}$.

El momento actual exige de manera urgente la reivindicación de una democracia que garantice, al modo de Nussbaum, unas capacidades para todos y todas que permitan una vida libre y con cierto bienestar. Está pidiendo un compromiso claro, honrado y riguroso de los educadores por un modelo de educación muy distinto al que se suele "ofertar» en nuestros días -que insta a la competitividad para crear trabajadores eficientes y eficaces a las órdenes del mercado (capitalista); que se burla de las humanidades y las reduce a su mínima expresión; que menosprecia el ámbito de las artes y, osado, se atreve a relegarlas a optativas en el currículum ${ }^{23}$; que entiende la calidad de la educación como el rendimiento académico del alumnado «medido» a través de pruebas estandarizadas ${ }^{24} \ldots-$. Un compromiso por un

22. "El significante "democracia" se ha convertido en un caso ejemplar de ausencia de significado: hemos insistido tanto en que esa palabra representa el sentido de la política virtuosa y en que es la única forma de garantizar el bien común que, así, el término ha acabado suprimiendo y disolviendo cualquier aspecto problemático, toda posibilidad de interpelación o de cuestionamiento. Lo único que subsiste, y a duras penas, son unos cuantos debates marginales sobre las diferencias existentes entre los distintos sistemas o las diferentes sensibilidades democráticas. En definitiva, el significado de la palabra "democracia" lo abarca todo -el ámbito político, de lo ético, del derecho, de la civilización- y, por consiguiente, no significa nada" (NANCY, 2010, 79).

23. Cfr. el carácter de la Educación Artística en la etapa de primaria en la la Ley Orgánica 8/2013, de 9 de diciembre, para la mejora de la calidad de la educación (LOMCE). Se considera materia específica y ello conlleva que el discente elegirá al menos una entre un repertorio de cuatro (Religión, Valores Sociales y Cívicos, Segunda Lengua Extranjera y Educación Artística).

24. No nos resistimos a incluir la siguiente reflexión de Nussbaum ante la nueva ley de educación, la Ley Orgánica 8/2013, de 9 de diciembre, para la mejora de la calidad de la educación (LOMCE), que continuamente habla de una serie de pruebas estandarizadas «objetivas» para medir el rendimiento académico de los alumnos: «El pensamiento crítico y la imaginación narrativa, al igual que las aptitudes necesarias para ser un buen ciudadano del mundo, no son capacidades que puedan evaluarse mediante pruebas cuantitativas de opciones múltiples. Consideremos, por ejemplo, cómo se habían de evaluar los conocimientos sobre historia mundial en un examen estandarizado: todo lo que propongo en cuanto al análisis de pruebas históricas, la crítica a los grandes relatos y el pensamiento crítico sobre las diferencias entre distintas narrativas quedaría omitido. El sistema de enseñanza enfocado en la aprobación de los exámenes, que se ha tornado cada vez más ubicuo en las aulas de las escuelas públicas, genera un clima de pasividad en los alumnos y de rutina para los docentes. La creatividad y la individualidad que 
modelo que bien pudiera tener como referencia la sociedad justa que se deduce del enfoque de las capacidades examinado, una comunidad de personas libres, tolerantes, con mentalidad abierta, solidarias, críticas, reflexivas, responsables, humanas.

Existen en nuestros días algunas propuestas y experiencias dentro de dicho enfoque con un resultado muy alentador. Melanie Walker, en el ámbito de la educación superior, confecciona una lista de ocho capacidades (razón práctica; resiliencia; conocimiento e imaginación; disposición al aprendizaje; relaciones sociales y redes sociales; respeto, dignidad y reconocimiento; integridad emocional, emociones; e integridad corporal) que deberían ser impulsadas en dicho nivel de enseñanza, insistiendo en que no se trata de un listado cerrado sino de un punto de partida para el debate (Walker, 2006, 128-129). Asimismo, en la Universidad de Sheffield, en el Reino Unido, se ha realizado una experiencia dentro del enfoque de las capacidades aplicado a la Universidad en 2007. El núcleo central era averiguar cómo pedagogías basadas en la investigación (research-enhanced pedagogies) posibilitan que la institución universitaria contribuya al desarrollo humano reequilibrando los objetivos de la educación superior para que contengan, además de oportunidades económicas, un enriquecimiento personal y el fomento de la ciudadanía democrática. El estudio no sólo se centró en los éxitos individuales y en el bienestar de los estudiantes sino también en el impacto en otros sujetos y en la sociedad en general. La conclusión fue que las pedagogías basadas en la investigación pueden contribuir como agentes responsables, seguros y críticos (cfr. Boni, Lozano y Walker, 2010, 129) ${ }^{25}$. Programas de educación emocional como el de Inteligencia emocional para la convivencia escolar (PIECE), de Vallés (2007); el de Habilidades emocionales para jóvenes de entre 12 y 18 años (INTEMO) de Ruiz, Cabello, Salguero, Palomera, Extremera y Fernández Berrocal (2013); el programa "Aprender a ser personas y a convivir: un programa para secundaria", de Trianes y Fernández-Figarés (2001), entre otros, guardan fuertes similitudes con las propuestas de Nussbaum.

Finalizamos con una frase muy bella de John Dewey que pronunció en el homenaje que le rindieron en su noventa cumpleaños: "La democracia empieza con la conversación» (Catalán, 2013, 83). Y es que realmente es el diálogo, primero con los otros, más tarde con nosotros mismos, lo que nos va haciendo personas, lo que nos humaniza. Un diálogo que para ser verdadero, para no ser una simple

caracterizan a los mejores tipos de educación humanística no encuentran espacio para desarrollarse en ese marco" (NussBaum, 2010, 178).

25. El proyecto destaca que las aproximaciones pedagógicas han de prestar atención al ser humano incluyendo: a) la adquisición de una perspectiva crítica en el conocimiento que se genera a través de la investigación mediante textos, las prácticas, los debates participativos con sus profesores y sus compañeros; b) el desarrollo de la confianza de cada estudiante en su habilidad para debatir en público, defender e incluso cambiar sus posiciones epistemológicas; c) respetar y entender diferentes perspectivas; d) potenciar las capacidades de los estudiantes para convertirse en "evaluadores fuertes" (cfr. BONI, LOZANO y WALKER, 2010, 129). 
pantomima, requiere como requisitos la humildad, el querer escuchar al otro, el estar dispuesto a aprender, el ser respetuoso con posturas contrarias, el estar interesado en llegar a la verdad... Ese diálogo que, a poco que pensemos, es el que está en la base en los tres elementos que Nussbaum ha destacado. El examen de uno mismo es diálogo interior, la ciudadanía mundial exige diálogo intercultural, la imaginación narrativa es el fomento de un requisito para entablar esa comunicación auténtica. Por eso, si en estas reflexiones quisieramos destacar un mensaje que Martha Nussbaum nos da a todos y especialmente a los educadores es que potenciemos el diálogo y que enseñemos a dialogar. Es la base de una cultura de paz y por tanto de la construcción de un mundo donde todos se puedan sentir acogidos, que pueda percibirse como un hogar ${ }^{26}$.

\section{REFERENCIAS BIBLIOGRÁFICAS}

ArTal, R. (2011) La sociedad desinformada, en ArTAl, R. M. ${ }^{a}$ (coord.) Reacciona, Diez razones por las que debes actuar frente a la crisis económica, política y social. Madrid, Aguilar, 95-110.

Bartolomé Pina, M. y Cabrera Rodríguez, F. (2003) Sociedad multicultural y ciudadanía: hacia una sociedad y ciudadanía interculturales. Revista de Educación. Número extraordinario, Ciudadanía y Educación, 33-56.

Bassas Vila, J. (2010) Gestos políticos. Presentación en la edición española en Agamben, G. y otros. Democracia en suspenso. Madrid, Casus Belli.

Benéitez Prudencio, J. J. (2009) Martha Nussbaum y Peter Euben y la educación socrática para la ciudadanía. Revista de Educación, 350, septiembre-diciembre, 401-422.

Benéitez Prudencio, J. J. (2010) La ciudadanía cosmopolita de Martha Nussbaum. Dáimon. Revista Internacional de Filosofía, Suplemento 3, 347-354.

Bisquerra, R. y PÉREz, N. (2007) Las competencias emocionales. Revista de Educación XXI, 10, 61-82. http://dx.doi.org/10.5944/educxx1.1.10.297.

Boni Aristizábal, A.; Lozano Aguilar, J. F. y Walker, M. (2010) La educación superior desde el enfoque de las capacidades. Una propuesta para el debate. REIFOP, 13 (3), 123-131.

Boynton, R. S. (1999) ¿Quién necesita la filosofía? Entrevista a Martha Nussbaum. The New York Times Magazine, noviembre. Traducción de Carme Castells: ¿Quién teme a Martha Nussbaum? Lectora, 9/2003, 3-10.

CAmps, V. (1997) Educar en democracia. Perspectivas, vol. xxvII, n. ${ }^{\circ} 4,529-535$.

Catalán, M. (2013) La ética de la democracia. Sobre la política de John Dewey. Madrid, editorial Verbum.

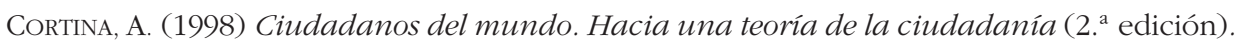
Madrid, Alianza editorial.

26. Coincidimos plenamente con Ángel García del Dujo y Ramón Mínguez Vallejos cuando afirman: «El civismo no se reduce sólo al reconocimiento y cumplimiento de unos deberes y unos derechos socio-políticos. Singularmente se amplía a un modo de ser humano aquí y ahora con los demás, de relación con el otro, con la naturaleza y con las instituciones sociales, donde la participación responsable en los asuntos públicos para hacer más humana la convivencia se convierte en el termómetro de la calidad cívica de sus ciudadanos” (García del Dujo y Mínguez Vallejos, 2011, 268). 
EL «ENFOQUE DE LAS CAPACIDADES» DE MARTHA NUSSBAUM Y SUS CONSECUENCIAS EDUCATIVAS...

Dewey, J. (1916) Democracy and Education. Nueva York, MacMillan.

Dewey, J. (1920) Reconstruction of Philosophy. London, H. Hold. University of London Press. http://dx.doi.org/10.1037/14162-000.

Dewey, J. (1938) Experience and Education. Illinois, Southern Illinois University Press. Traducción española de 1954: Experiencia y Educación. Buenos Aires, Losada.

FeINBERG, W. (1998) Common schools/Uncommon identities; National unity and cultural difference. New Haven y Londres, Yale University Press.

FreIRE, P. (1978) La educación como práctica de la libertad. México, Siglo XXI.

Gamper, D. (2010) Filosofía contra la desdicha. La Vanguardia, Sección Cultura/s, 15 de septiembre, 3 .

García del Dujo, Á. y Mínguez Vallejos, R. (2011) Los límites de la educación en valores cívicos: cuestiones y propuestas pedagógicas. Educación XXI, 14.2, 263-285.

González BARRón, R. y Villanueva Badenes, L. (2014) Recursos para educar en emociones. De la teoría a la acción. Madrid, Pirámide.

Guichot-Reina, V. (2012) Tolerancia, una virtud cívica clave en una educación para la ciudadanía activa, compleja e intercultural. Bordón, 64 (4), 35-47.

Guichot-Reina, V. (2013) La capacidad reflexiva, factor esencial de la identidad profesional del profesorado: reflexiones en torno a las propuestas de John Dewey y Martha Nussbaum. Cuestiones Pedagógicas, 22, 183-202.

Nancy, J. L. (2011) Democracia finita e infinita, en Agamben, G. y otros. Democracia en suspenso. Madrid, eds. Casus Belli, 79-96.

Nussbaum, M. C. (1997) Cultivating Humanities: A Classical Defense of Reform in Liberal Education. Harvard University Press. Traducción española de 2001: El cultivo de la humanidad. Una defensa clásica de la reforma en la educación liberal. Barcelona, editorial Andrés Bello.

Nussbaum, M. C. (1999) Los límites del patriotismo. Identidad, pertenencia y "ciudadanía mundials. Barcelona, Paidós.

Nussbaum, M. C. (2000) Aristotle, Politics, and Human Capabilities: A Response to Antony, Arenson, Charlesworth, and Mulgan. Ethics, 11, October, 102-140. http://dx.doi. org/10.1086/233421.

Nussbaum, M. C. (2007) Las fronteras de la justicia. Barcelona, Paidós.

Nussbaum, M. C. (2010) Not for profit. Why democracy needs the humanities. Princeton, NJ, Princeton University Press. Traducción española de 2010: Sin fines de lucro. Por qué la democracia necesita de las humanidades. Madrid, Katz editores.

Nussbaum, M. C. (2012) Crear capacidades. Propuestas para el desarrollo bumano. Barcelona, Paidós.

Nussbaum, M. C. (2012) Discurso pronunciado al recibir el Premio Príncipe de Asturias de Ciencias Sociales, página web de la Fundación Príncipe de Asturias <www.fpa.es>.

Nussbaum, M. C. (2014) Emociones políticas. ¿Por qué el amor es importante para la justicia? Barcelona, Paidós.

Platón (2002) Apología de Sócrates; Fedón. Madrid, Consejo Superior de Investigaciones Científicas.

Rawls, J. (1971) A Theory of Justice. Oxford, Oxford U.P.

Rawls, J. (1993) Political Liberalism. New York, Columbia University Press.

ROBERTSOn, R. (1992) Globalization. Londres, Sage. 
Rubio Carracedo, J. (2000) Ciudadanía compleja y democracia, en Rubio Carracedo, J.; Rosales, J. M. a y TOSCANo Méndez, M. Ciudadanía, nacionalismo y derechos humanos. Madrid, Trotta, 21-45.

Ruiz, D.; Cabella, R.; Salguero, J.; Palomera, R.; Extremera, N. y Fernández-Berrocal, P. (2013) Guía para mejorar la inteligencia emocional de los adolescentes. Programa INTEMO. Madrid, Pirámide.

SAmpedro, J. L. (2011) Debajo de la alfombra, en ArTal, R. M. ${ }^{a}$ (coord.) Reacciona, Diez razones por las que debes actuar frente a la crisis económica, política y social. Madrid, Aguilar, 15-23.

SEN, A. (1989) Sobre ética y economía. Madrid, Alianza.

SEn, A. (1997) Bienestar, justicia y mercado. Barcelona, Paidós ICE/UAB.

Sen, A. (1999) Development as Freedom. Oxford, Oxford University Press. Traducción castellana: Desarrollo y libertad. Barcelona, Planeta, 2000.

TORRes López, J. (2011) Una crisis de verdad y muchas mentiras como respuesta, en ARTAL, R. M. ${ }^{a}$ (coord.) Reacciona, Diez razones por las que debes actuar frente a la crisis económica, política y social. Madrid, Aguilar, 63-75.

Trianes, M. V. y FernándeZ-Figarés, C. (2001) Aprender a ser personas y a convivir. Un programa para secundaria. Bilbao, Declée de Brouwer.

VALLÉs, A. (2007) Inteligencia emocional para la convivencia escolar. El programa PIECE. Madrid, EOS.

Vilafranca, I. y BuXARrais, R. (2009) La educación para la ciudadanía en clave cosmopolita. La propuesta de Martha Nussbaum. Revista Española de Pedagogía, año LXVII, n. ${ }^{\circ} 242$, enero-abril, 115-130.

Walker, M. (2006) Higher education Pedagogies. Berkshire, The society for Research into Higher Education and Open University Press. 